Journal of Energy and
Environmental Sustainability
Journal homepage : www.jees.in

\title{
Design and Development of a Novel PM Inertial Impactor With Reduced Particle Bounce Off
}

\author{
Kaniska Biswas ${ }^{1}$ and Tarun Gupta ${ }^{1,2 *}$ \\ ${ }^{1}$ Design Program and ${ }^{2}$ Department of Civil Engineering, IIT Kanpur
}

\section{A R T I C L E I N F O}

Received : 11 March 2017

Revised : 27 May 2017

Accepted : 31 May 2017

Keywords:

Off-centric impactor, particle bounce-off, impactor nozzle plate, silicone grease,

impaction plate.

\begin{abstract}
A B S T R A C T
Air quality engineers carry out air sampling for monitoring the air pollutants, finding key sources of pollutants and assessing the health risk associated with them. Inertial impactors are simple devices based on impaction theory and useful for size specific collection of aerosol particles. Inertial impactors have one major problem of particle bounce off which perturbs its accuracy and collection efficiency. This problem is non-predictable and increases with longer sampling period. It is also pronounced with increased pollution level. This present study presents design and development of a novel inertial impactor having an off-centric impaction nozzle as a solution to reduce particle bounce off.
\end{abstract}

\section{Introduction}

Bad air quality in urban areas has become a major issue across the globe. The simultaneous increase in population and pollution has created potential health issues due to the emission of various harmful gases (carbon dioxide, methane, oxides of nitrogen and sulfur) and particulate matters. The major sources of particulate matters include burning of biomass, industrial process, emission from power plants and diesel vehicle (Chakraborty and Gupta, 2010). Urban areas are facing serious threat from air pollution related health issues due to the presence of higher concentration of anthropogenic sources. Air has a wide range of suspended particulate matters, called aerosols. Amongst all size ranges, PM2.5 (particulate matters having aerodynamic diameter 2.5 micron or less) is of significant concern. This size range is proved to have direct harmful effect on human health. It is even more detrimental to the sensitive population including elderly and diseased and affects human cardiovascular and respiratory system (Pope et al., 2002). The adverse health effect caused by particulate matters is more pronounced when they are of finer sizes (Donaldson and MacNee, 1998; Ferin et al. 1999). Finer size range has the potential to penetrate deep into the lungs and eventually enters into the blood.(Schwartz et al. 1996; Harrison and Yin, 2000; Cohen et al., 2005; Kunzli and Tager, 2005; Sharma and Agrawal, 2005; Huang and Ghio, 2006).
It is, therefore, necessary to know the air pollution level and recognize the source control strategies for its abatement. Air pollution engineers are interested in size specific collection of those target size range $\left(\mathrm{PM}_{25}\right.$ or PM1) followed by extensive chemical analysis in the laboratory. Several instruments and methods are available for the size specific collection of particulate matters; but the most common and simple device which can separate and collect aerosol particles size specifically is the impactor. The impactor is based on the impaction theory and separates larger particles from smaller ones based on inertia difference (Liu, 1976).

\section{Theory of Impaction}

Impactors are widely used for sampling and separation of airborne particulate matters because of their sharp separation, high collection abilities, and relatively simple design. Researchers have already come up with theoretical equations and curves to accurately predict the design parameters (Marple and Willeke, 1976; McFarland et al., 1978). Several types of inertial impactors are developed so far (Marple et al., 1991; Demokritou et al., 2002a,2000b, 2000c; Furuuchi et al., 2010) and proved to be an excellent substitute to costly optical based particle spectrometers (Liu et al., 2010).

\footnotetext{
* Corresponding Author: tarun@iitk.ac.in
} 
Detail description of different parts of an impactor has been shown in Fig. 1. Impactor comprises majorly of an impaction nozzle and impaction plate. The impaction nozzle acts as a gateway of the air stream containing both target and non-targeted particle size distribution. Air entrains by the suction of an air pump attached downstream to the impactor. Comparatively, bigger particles with sufficient inertia will slip the air stream and hit the impaction surface. Target particle range of smaller size and less inertia will be there in the air streamline and finally get collected on a filter paper of much finer mesh size (Hinds, 1999).

$\mathrm{W}=$ Nozzle width at the exit of the air stream flow; $\mathrm{S}=$ Distance between nozzle exit and impaction surface

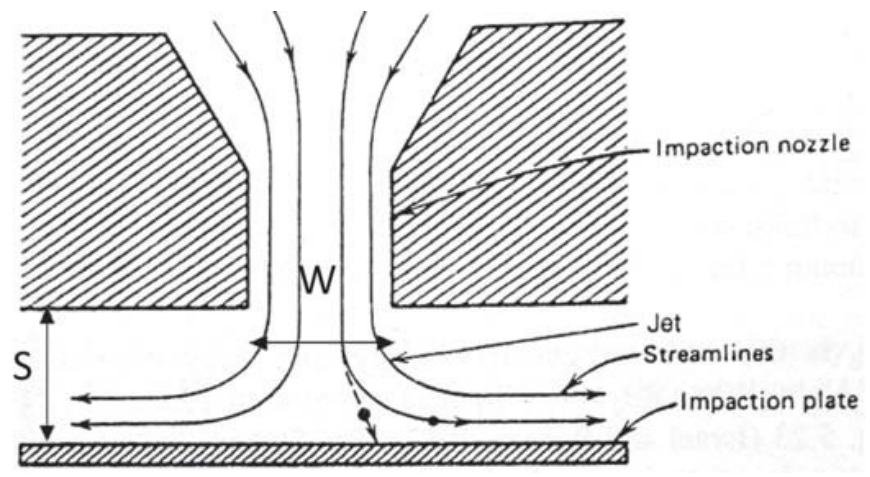

Figure 1: Cross-sectional view of an impactor (Hinds, 1999

According to the impaction theory, the cut point diameter is calculated by using the dimensionless Stokes number (Stk). Stk is the main governing parameter and is defined as follows:

$$
S t k=\frac{\rho_{p} d_{p}^{2} U C_{c}}{9 \eta D_{j}}
$$

Where, $\rho_{\mathrm{p}}$ is the particle density $\left(\mathrm{kg} / \mathrm{m}^{3}\right)$, ç the air dynamic viscosity (Pa.s), $\mathrm{d}$ is particle diameter $(\mu \mathrm{m}), U$ is jet velocity in theimpactor nozzle $(\mathrm{m} / \mathrm{s})$, $D_{i}$ is nozzle diameter $(m)$, and $C$ is the Cunninghamslip correction factor, and $\mathrm{P}$ is absolute pressure $(\mathrm{kPa})$ (Baron and Willeke, 2001).

$$
C_{c}=1+\frac{1}{P d_{p}}\left[15.60+7.00 \exp \left(-0.059 P d_{p}\right)\right]
$$

The theoretical cutoff diameter $\left(\mathrm{d}_{50}\right)$ is calculated by using the following equation (Hinds, 1999).

$$
d_{50} \sqrt{C_{c}}=\left[\frac{9 \Pi \eta D_{j}^{3}\left(S t k_{50}\right)}{4 \rho_{p} Q}\right]^{1 / 2}
$$

Where $\mathrm{Q}$ is the flow rate $\left(\mathrm{m}^{3} / \mathrm{s}\right)$ and $\mathrm{Stk}_{50}$ is the Stokes number for $50 \%$ collection efficiency for impactors.

This equation fits well for flat impaction surfaces. The Reynolds number (Re) can also be calculated by using the following equation.

$$
R e=\left(\rho_{\text {air }} U D_{j}\right) / \eta
$$

Where $\rho_{\text {air }}$ is the air density $\left(\mathrm{g} / \mathrm{m}^{3}\right), \mathrm{U}$ is the flow velocity $(\mathrm{m} / \mathrm{s})$.

For obtaining the desired sharp cut off, the recommended Reynolds number of the gas flow in the nozzle exit should be between 500 and 3000 (Hinds, 1999).

The basic structure of an inertial impactor is given in figure 2. It consists of an impaction nozzle, impaction plate, filter paper holding assembly and an air suction funnel. The air suction funnel is attached with rotameter, a flow control device, and then with air suction pump. Any impactor is designed for a particular flow condition and the pump assisted with a flow controller device helps to achieve the same. Impaction nozzle plate in the first component in the upstream and air flows through the conical nozzle. This conical nozzle helps the airflow to be projected on an impaction surface. Impaction plate is placed in the downstream to the nozzle plate and contains a cavity filled with impaction substrate. High density silicone grease is commonly used as the impaction substrate. Around the impaction region at the center, holes are made so that finer

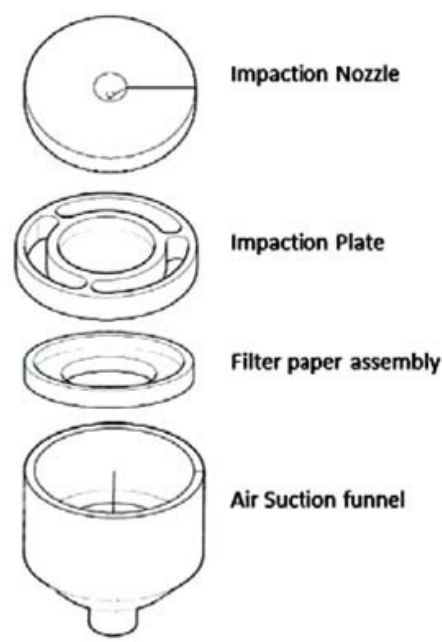

Figure 2: Basic structure of an Impactor

particles can escape hitting the impaction surface and gets collected onto the filter paper placed downstream to the impaction plate. Air is sucked out by the pump and the air suction funnel provides a uniform suction pressure on the filter paper. It helps in uniform collection of the targeted particulates on the filter paper.

Even though the impactor-based air sampler is well known but major problems of particle bounce off and non-consistency of S/W ratio (Fig. 1) are there in the existing impaction based air sampling apparatus (Liu, 1976). As discussed, inertial impactor contains impaction nozzle and impaction plate. On the impaction plate, impaction substrate (highviscosity grease) is used to capture the larger and non-targeted particles (Turner \& Hering,1987). The impactor is designed in such a way that the particles below the design cut-point, only get access to bend sharply and escape the impaction plate (Hinds, 1999).

However, in the present scenario, the impaction substrate gets exhausted as the larger particles get captured and eventually cover the impaction substrate. With the progress of air sampling the particle capturing capacityof the high-density silicone grease get decreased (Turner \& Hering, 1986). New larger particles do not get the access to get collected onto the impactor substrate anymore. They hit on the previously captured particles on the impaction substrate rather than hitting the impaction substrate itself. As a result, they are bounced off from the surface and re-enter the main air stream flow. Reduction of particle bounce-off is important for better reliability of test result, as it disturbs the inflow and perturbs the assumptions of impaction theory.

For a long duration sampling, the larger particles being collected at a single point on the impaction substrate forms a tiny heap (Gupta et al., 2011) on the substrate which not only promotes particle bounce off but also alters the jet to plate distance. In impactor design, the S/W ratio is one of the design parameters that should be maintained through the sampling duration (Marple \& Willeke, 1976).

\section{Methods}

Both the problems (particle bounce off and non-consistent ' $\mathrm{S} / \mathrm{W}$ ' ratio), as discussed, are generated due to a single issue, the accumulation of non-target larger particles on a single point. So, it was decided to distribute the entire particle loading into multiple points. It was well understood that, on the accumulation of particles at a single point in a high loading condition, older particles will soon cover the impaction surface. When new particles will come they will not be exposed to the sticky impaction substrate, rather they will hit on older particles and eventually cause particle bounce-off (Turner \& Hering, 1987).

In inertial impactors, the particles should retain in the impaction surface after getting impacted on to it. But this ideal condition is not always achieved and thus the size distribution is affected. Dry solid particles use to bounce from the impaction surface and reenter into the main flow and perturbs the reliability of results. Minimizing particle bounce-off, is therefore a challenge to the air pollution engineers. The problem of particle bounce-off was identified during the initial development of cascade impactors (May, 1945). This problem became acute for sampling in dry and desert areas. In order to reduce the problem of particle bounce-off, different types of impaction surface have been used for absorbing the 
particle kinetic energy. Glass fiber mat was used previously but was proved to be ineffective as it collects particulates smaller than the cut-off diameter. High density grease coating is also used and proved to be effective at the initial stage, but its efficiency gets reduced with progress of time (Reischl and John, 1978).According to the study conducted by Rao and Whitby (1978a, 1978b) the greased surfaces can hold particles better than dry surfaces or glass fiber filters. The similar results were found by the study conducted by Cushing et al., 1979, Lawson 1980 and Dzubay et al.,1976. The particle holding capacity of greased surface decreases sharply and found to be useless when particle loading is high (Turner and Hering, 1987).

To reduce the particle bounce-off, fresh impaction surfaceshould be providedin order to maintain the capturing ability unaltered.The fresh impaction surface can be provided either by changing the impaction plate or replacing the older grease with fresh one when it gets exhausted. With simple means, changing the impaction platecan be difficult to achieve.It was observed from the previous studies that the larger particulates are impacted at the center of the circular impaction region and rest of the portion remains unused (Gupta et al., 2011). So, another solution can be the utilization of the unused portion of the impaction surface which is eventually the same idea of providing a new surface. This can be achieved by changing the relative position of the nozzle and the impaction surface. In the conventional design with a centrally placed impaction nozzle it was not possible to find a new impaction location even by providing relative rotational movement between the nozzle plate and impaction plate. So,in this novel design the impaction nozzle is designed to be slightly off-centric. The rotation of the nozzle plateafter a certain time interval (1-2 hour, depending upon the total sampling period and the pollution level), enables to find out new deposition locations on the same impaction substrate. Each time after rotation, the impaction nozzle will focus its air stream flow to a new point which is fresh and sticky to hold the new particles with better efficiency. As the total loading was decided to be distributed to 4-6 different points, the heap will not form and the distance between nozzle outlet and impaction substrate will not be affected much. Impaction theory suggests an impaction area with minimum ' $4 \mathrm{~W}$ ' diameter. (Marple, 1970). With off-centric nozzle and with eccentricity 'W', the impaction region was designed to be ' $6 \mathrm{~W}$ ' in diameter to ensure a minimum ' $4 \mathrm{~W}$ ' distance from all side. As per the assumptions of impaction theory, the flow must be laminar all the time and thus any disturbance in the flow must be avoided. So, the relative rotation of the nozzle plate with respect to the impaction plate should not happen while sampling is going on. Previous studies show that the particle retaining capacity of high-density is good at initial stage but get exhausted with time (Turner and Hering, 1987). So, rather than changing the impaction surface continuously, it is needed to be changed after certain time interval.Hence the plan of rotating the nozzle plate after 1-2 hour fits perfectly in this scenario. Before each rotation, the air suction pump must be switched off and then the nozzle plate should rotate to a predefined angle. After each rotation, the pump will start for the next run.

In the present study, the design parameters for $\mathrm{PM}_{25}$ impactornozzle were adopted from previous research done at our laboratory (Gupta et al., 2011). The solution of distributing the total particle mass into multiple points instead of a single point, is generic and can be applied to all inertial impactors based with different cut-off diameter. For designing the complete structure of such an impaction based PM sampler, the operational steps of the user (operator) were observed and analyzed. The major operation is to manually replace the old filter paper with a new one and to change the impaction surface with a fresh one. The filter papers used for such sampling are delicate Teflon or Quartz filters and need proper care at the time of collection and replacement. So, it was decided to design the entire assembly in such a way that it can be opened at two different segments. Opening from one segment will enable the operator to access only the filter paper and the other will enable access to impaction plate. This will provide ease to the operator to change the filter paper and the impaction surface individually without disturbing the other one.

Experiments were conducted to observephysically the application of the present invention. A conventional $\mathrm{PM}_{2.5}$ impactor and the newly developed impactor with off-centric nozzle were placed on the terrace of the Environmental building, IIT Kanpur. Both of them were run at 15 LPM flow rate for 4 hour. The conventional $\mathrm{PM}_{2.5}$ impactor was undisturbed throughout the period but the nozzle plate of the off-centric one was rotated at 90-degree angle after each hour. After 4 hour of sampling both the impactors were stopped and the impaction plates from both the impactor were carefully taken out and compared visually.

\section{Result and Discussion}

\subsection{Description of the novel inertial impactor with reduced particle bounce-} off.

The newly developed PM air sampler (Fig. 3a) majorly consists of the following parts:I) Air inlet cap and rain protection, II) Upper casing, III) Impaction nozzle, IV) Teflon bush, V) Impaction plate, VI) Impaction plate holder, VII) Wire mesh, VIII) Filter paper holder, IX) Base holder. These individual components have been shown in Fig. 3b. These individual components are being further categorized into 3 segments, the upper part, the middle part and the lower part. The upper part consists of components I), II), III) and IV). The middle part comprises of components V) and VI). The lower part includes component VII), VIII) and IX).
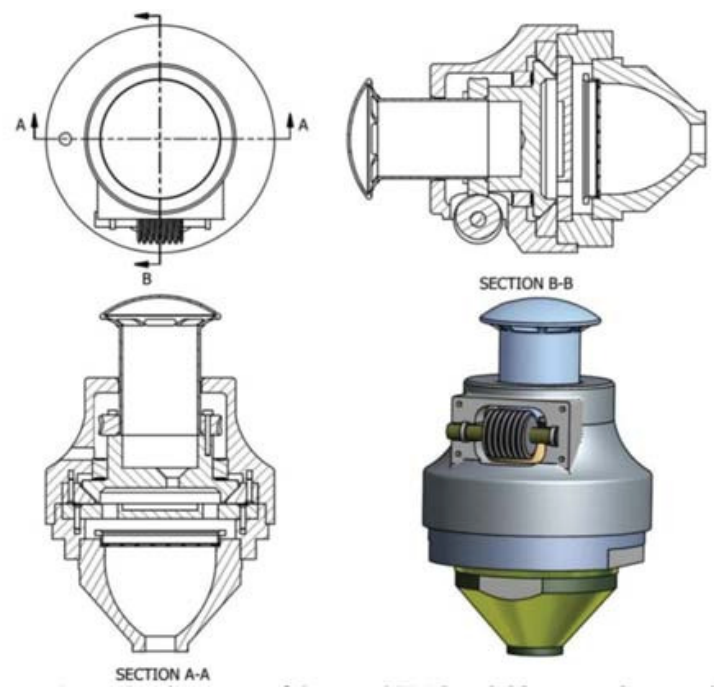

Figure 3a: Structure of the novel PM inertial impactor in assembled form

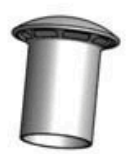

I) Air inlet cap and rain protection

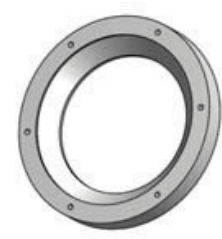

IV) Teflon bush
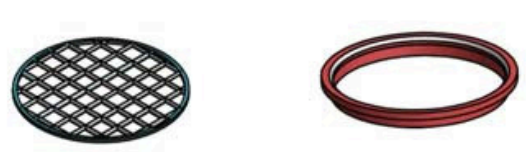

VII) Wire mesh

II) Upper casing

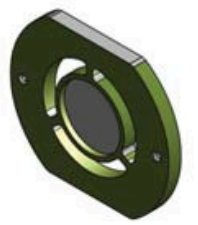

V) Impaction plate

VIII) Filter paper holder

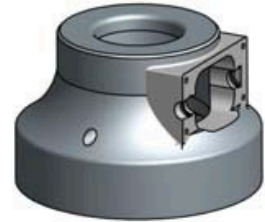

VI) Impaction plate holder

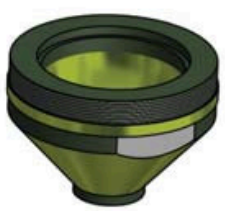

IX) Base holder

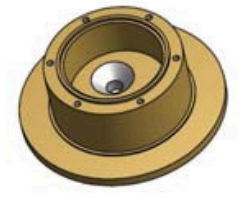

III) Impaction nozzle

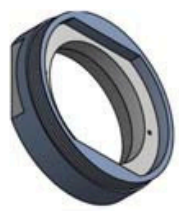

Figure 3b: Individual components of the novel inertial impactor 
The upper part of the PM inertial impactor (Fig. 4) contains the air inlet cap and rain protection (Fig. $3 \mathrm{~b} \mathrm{I}$ ) as the first component at the upstream. It allows the entrance of air to the Impaction nozzle. It also protects the sampling from the direct entry of rain water into the flow. The upper casing (Fig. $3 \mathrm{~b}$ II) is designed to adopt the warm gear mechanism. It also fits the off-centric impaction nozzle and teflon bush inside it. The impaction nozzle (Fig. 3b III) rotates with the help of warm gear mechanism and a stepper motor. The teflon bush (Fig. 3b IV) holds the impaction nozzle and is being screwed with the upper casing part. It also provides minimum friction to the rotating nozzledue to its smooth surface.
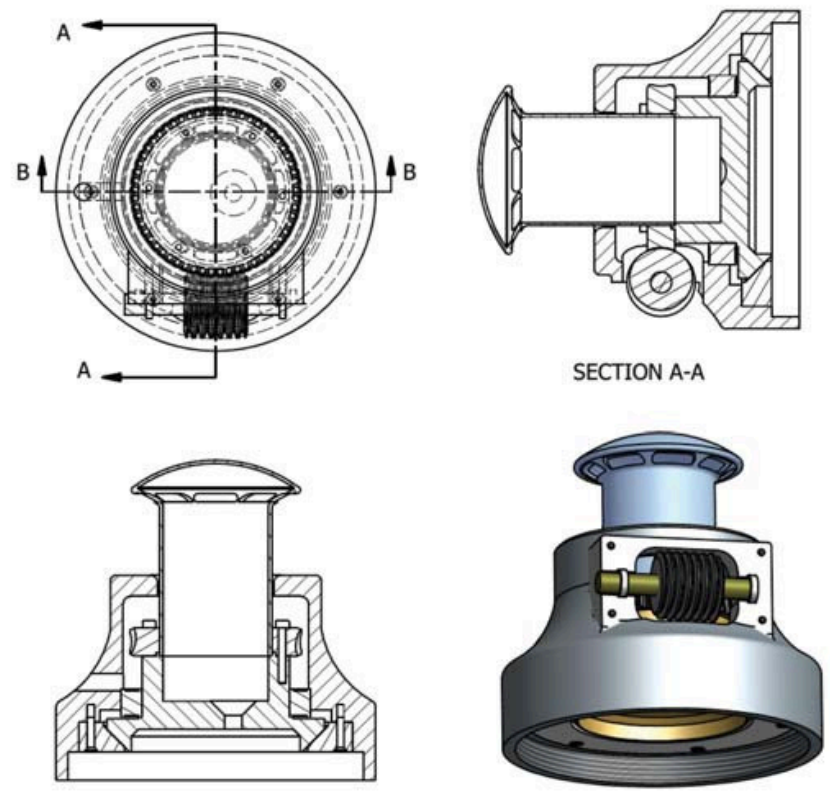

SECTION B-B

Figure 4: Drawings of the upper part of the novel PM inertial impactor

The impaction plate holder (Fig. 3b VI) holds the impaction plate (Fig. 3b V) and these two consist the middle part (Fig. 5), and can be easily detached from the upper part. A slot in the impaction plate holder is designed in such a way that the impaction plate fits perfectly inside it. Threads are provided at the outer surface of the impaction plate holder and at the inner side of the upper casing. This arrangement enables the impaction plate holder to be attached inside the upper casing.
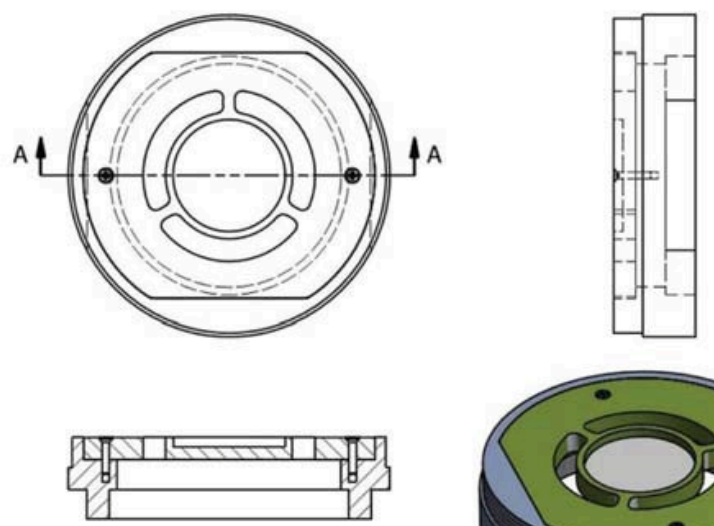

SECTION A-A

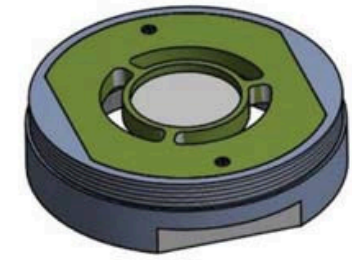

Figure 5: Drawings of the middle part of the novel PM inertial impactor
The lower part (Fig. 6) is designed for collecting particulate matters of target sized on standard teflon or quartz filter paper and is at the downstream of the impaction plate. This part comprises of a wire mess (Fig. 3b VII) to support the filter paper, and a filter paper holder (Fig. 3b VIII) is also designed for keeping the filter paper at right position during sampling. The base holder(Fig. 3b IX) is designed as a casing to hold the wire mesh and the filter paper holder inside it. An air suction pump is attached at the downstream of the base holder and assisted by rotameter for providing the required design flow rate. The base holder is a funnel like structure which distributes the air suction pressure uniformly to the filter paper. The base holder comprises with threads at its outer periphery.Other than the threads made on the outer periphery, impaction plate holder also has threads at the inside. Its inner threading allows the base holder portion to be attached inside it. In this design, the Impaction plate can be accessed without disturbing the filter paper for replacing the impaction substrate. The filter paper can also be accessed and replaced without disturbing the upper portion and only by removing the base holder.
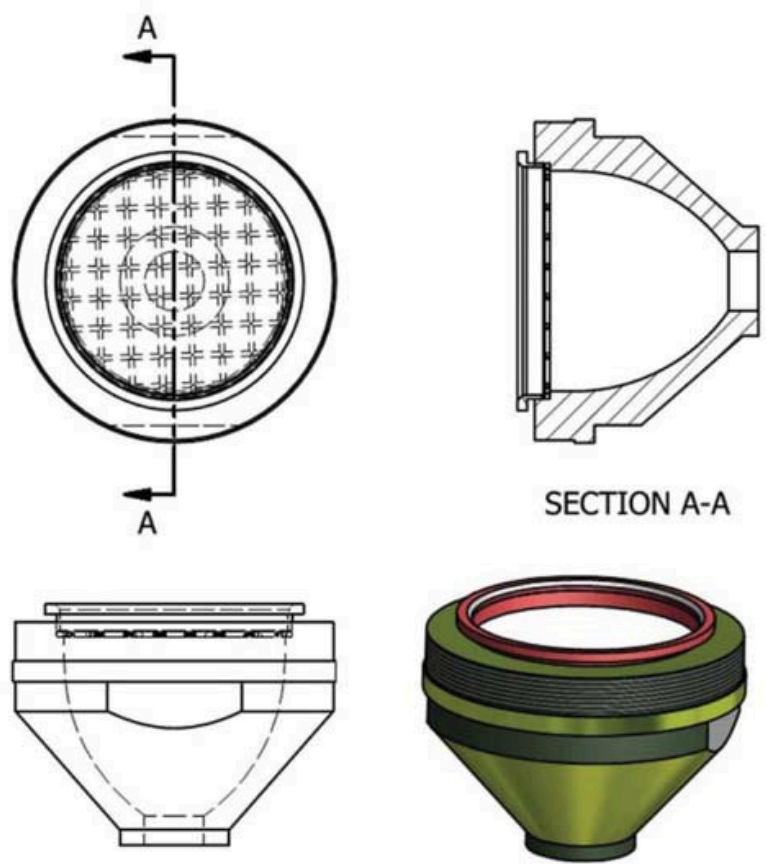

Figure 6: Drawings of the lower part of the novel PM inertial impactor

\subsection{Results of field evaluation, co-located sampling}

The newly developed impactor and a conventional PM impactor were run for co-located sampling on the terrace of the Environmental building, IIT Kanpur for 4 hour at 15 LPM. After 4 hour of sampling, both the impaction plates are taken out for comparison. With this new arrangement, it formed four distinct deposition points on the impaction surface. The total load generated from non-targeted particles forms a singular point on the impaction surface of the conventional impactor whereas with the off-centric arrangement, the same particulate load is evenly distributed to four points. It is needless to say, in this case, the loading at each distinct point is reduced. With simple visual comparison, it is clearly seen that the 4 individual heaps formed from particle deposition are of a much smaller size in comparison with the one single heap formed at the conventional impactor.

\section{Conclusion}

Particle bounce off is an innately associated problem in impaction based air sampling methodology and promotes errors in scientific research. The problem was not in the impaction theory; it was in the design of the impactor.In the development of this novel impactor, simple concepts like load distribution has been used. Just by distributing the total captured particulates into 4 different points, particle bounce off gets reduced. From the visual comparison of the two impaction plates after sampling, it can be stated that particle bounce off problem is now reduced. 4 spots from the new impactor are clearly smaller than the single spot generated in the 
conventional one. This clearly indicates that less particle bounce off will take place with this novel design. The solution is generic and can be applied to any inertial impactor to achieve less particle bounce off. The number of deposition points and the time interval can also be changed according to the requirement.

\section{Acknowledgements}

We thank MHRD and IIT Kanpur for partial funds for this study. An Indian patent application 201611022179 dated June 28, 2016 has been filed by SIDBI, IIT Kanpur on this work.

\section{References}

[1] Baron P.A, Willeke K, editors, 2001, Aerosol measurement. 2nd ed. New York: John Willey \&Sons Inc.

[2] Chakraborty A, Gupta T, 2010, Chemical characterization and source apportionment ofsubmicron (PM1) aerosol in Kanpur region, India. Aerosol Air Qual. Res.,10,43345

[3] Cushing, K. M., McCain, M. D. and Smith, W. B., 1979, Experimental determination of sizing parameters and wall losses of five source-test cascade impactors. Envir. Sci. Technol. 13, 726-731

[4] Demokritou P, Kavouras I. G, Ferguson S. T, Koutrakis P, 2002, Development of a High Volume Cascade Impactor for Toxicological and Chemical Characterization Studies,Aerosol Science and Technology.36(9), 925-933

[5] Demokritou P, Gupta T, Ferguson S, Koutrakis P, 2002, Development and laboratory performance evaluation of a personal cascade impactor,Journal of the Air \& Waste Management Association, 52,1230-1237

[6] Demokritou P, Gupta T, Ferguson S, Koutrakis P, 2002, Development and laboratory characterization of a prototype coarse particle concentrator for inhalation toxicological studies, Journal of Aerosol Science 33,1111-1123

[7] Donaldson K, MacNee W, 1998, The Mechanism of Lung Injury Caused by PM10. In: R. E. Hester \& R. M. Harrison (Eds.), Air Pollution and Health, The Royal Society of Chemistry, 10, 21-32

[8] Dzubay, T. H., Hines, L. E. and Stevens, R. K., 1976, Particle bounce errors in cascade impactors. Atmos. Envir. 10, 229-234

[9] Furuuchi M, Choosong T, Hata M, Otani Y, Tekasakul P, Takizawa M, 2010, Development of a personal sampler for evaluating exposure to ultrafine particles.
Aerosol and Air Quality Research, 10(1), 30-37

[10] GuptaT, Jaiprakash, Dubey S, 2011, Field performance evaluation of a newly developed PM2.5 sampler at IIT Kanpur,Science of the Total Environment, 409(18), 3500-3507

[11] Hinds WC, 1999, Aerosol technology, John Willey and Sons Inc, New York

[12] Lawson, D. R. 1980, Impaction surface coatings intercomparison and measurements with cascade impactors. Atraos. Envir. 14, 195-199

[13] Liu, Benjamin Y H, 1976, Inertial impactors: Theory, Design and Use. In: Fine particles Aerosol Generation, Measurement, Sampling, and Analysis, Academic Press, Inc, New York San Francisco London pp. 411-445

[14] Liu, Benjamin Y H, Romay F J, Dick W D, Woo K S, Chiruta M, 2010, A wide-range particle spectrophotometer for aerosol measurement from $0.010 \mu \mathrm{m}$ to $10 \mu \mathrm{m}$. Aerosol Air Qualitative Research10, 125-39

[15] Marple, V.A., 1970, Ph.D. Dissertation, Department of Mechanical Engineering, University of Minnesota, Minneapolis, MN

[16] Marple V A, Willeke K, 1976, Impactor design, Atmospheric Environment 10, 891 896

[17] Marple VA, Rubow K L, Behm S, 1991, A micro orifice uniform deposit impactor (MOUDI): description, calibration and use,Aerosol Science Technology 14, 434446

[18] May, K. R, 1945, The cascade impactor: an instrument for sampling coarse aerosols, J. Scient. Instrum. 22, 187-195

[19] McFarland A R, Ortiz CA, Bertsch RWJ, 1978, Particle collection characteristics of a single-stage dichotomous sampler, Environmental Science and Technology 12,679-682

[20] Pope C A, Burnett RT, Thun M J, Calle E E, Krewski D, Ito K, Thurston G D, 2002 Lung cancer, cardiopulmonary mortality, and long-term exposure to fine particulate air pollution. Journal of the American Medical Association, 287(9), 1132-1141

[21] Rao, A. K. and Whitby, K.T., 1978a,Non-ideal collection characteristics of inertia impactors I: single-stage impactors and solid particles. J. Aerosol Sci. 9, 77-86

[22] Rao, A. K. and Whitby, K. T., 1978b, Non-ideal collection characteristics of inertial impactors II: cascade impactors. J. Aerosol Sci. 9, 87-100

[23] Reischl, G. P. and John, W., 1978, The collection efficiency of impaction surfaces Staub. Reinhalt. Luft. 38,55

[24] Turner J R, Hering S V, 1987, Greased and oiled substrates as bounce-free impaction surfaces, Journal of Aerosol Science 18(2), 215-224 